\title{
Psychosocial factors that mediate the association between mode of birth and maternal postnatal adjustment: findings from a population-based survey
}

Fiona Alderdice ${ }^{1 *}$ (D) Jane Henderson ${ }^{1}$, Charles Opondo ${ }^{1}$, Marci Lobel ${ }^{2}$, Maria Quigley ${ }^{1}$ and Maggie Redshaw ${ }^{1}$

\begin{abstract}
Background: Mode of birth has been found to be associated with maternal postnatal adjustment with women who have Caesarean Sections (CS) thought to be at higher risk of emotional distress. However the relationship is complex and studies have demonstrated mixed findings. The aim of this study is to evaluate a model that explores the direct relationship between mode of birth and postnatal maternal adjustment at 3 months and indirect relationships through psychosocial variables.

Methods: A secondary analysis of a population-based survey conducted in England, UK in 2014. The analysis included primiparous women with singleton babies who provided information about mode of birth $(n=2139)$.

Results: Maternal postnatal adjustment, as measured by Maternal postnatal wellbeing and Satisfaction with care during labour and birth, varied by mode of birth. Women who had an unplanned CS had the poorest postnatal adjustment. Mode of birth was not associated with Maternal/infant sense of belonging. Four out of the five proposed mediation variables (Perceived control, Maternal expectation, Support in labour, How long until the mother held her baby), showed partial mediation of the relationship between mode of birth and both Maternal postnatal wellbeing and Satisfaction with care during labour and birth. The strongest mediator was Perceived control and the only variable not to show a significant mediation effect was Health of the infant at 3 months.

Conclusions: Birth by unplanned, but not planned, caesarean section was associated with poorer maternal adjustment and instrumental birth was associated with lower maternal satisfaction with labour and birth. These relationships were found to be partially mediated by psychosocial variables. Psychosocial interventions in the perinatal period should be considered to optimise maternal postnatal adjustment.
\end{abstract}

Keywords: Mode of birth, Maternal postnatal adjustment, Psychosocial, Mediation

\section{Background}

An increase in births by Caesarean Section (CS) globally, has highlighted concerns that women who experience CS may have poorer physical and psychosocial adjustment after birth [1-3]. Physical outcomes have been relatively well documented, however, the relationship between mode of birth and psychosocial outcomes would appear to be

\footnotetext{
* Correspondence: Fiona.alderdice@npeu.ox.ac.uk

${ }^{1}$ Policy Research Unit in Maternal Health and Care, National Perinatal Epidemiology Unit, Nuffield Department of Population Health, University of Oxford, Old Road Campus, Headington, Oxford OX3 7LF, UK

Full list of author information is available at the end of the article
}

complex with studies to date demonstrating mixed findings $[4,5]$.

A review by Lobel and DeLuca (2007) found that women who deliver by CS had more negative perceptions of their birth experience, themselves and their infants. They demonstrated poorer parenting behaviour and may be at higher risk of emotional distress in comparison to women who had a vaginal birth. These findings have been borne out in further studies with mode of birth being shown to be associated with postnatal depression [6-8], post-traumatic stress disorder [9-11] and poorer adjustment to parenthood $[12,13]$. The findings, however, are

(c) The Author(s). 2019 Open Access This article is distributed under the terms of the Creative Commons Attribution 4.0 International License (http://creativecommons.org/licenses/by/4.0/), which permits unrestricted use, distribution, and 
not consistent and other studies have shown that planned CS has a favourable impact [14] or they have not found an association between mode of birth and these psychosocial outcomes [15-20].

Historically, many of these studies have been small and based on convenience samples and inconsistent findings may reflect these methodological limitations [4]. However, there have been variations in the aspects of mode of birth and how maternal postnatal adjustment has been defined that may explain inconsistencies that continue to be observed. For example, there has been variability in the different categories of mode of birth studied with some studies comparing CS or instrumental birth to spontaneous vaginal birth (SVD) and others focusing on planned versus unplanned birth. Sadat et al. (2014) found no association between mode of delivery and postpartum depression, however CS was not differentiated into planned and unplanned CS [21]. If there is time to plan the procedure for the health of the mother or baby the benefits and risks of a caesarean compared with a vaginal birth will be discussed with a health professional in advance of labour and birth. Unplanned CS occurs when a problem arises such as fetal or maternal distress. As the decision-making and the context of care are very different between planned and unplanned CS it is important to differentiate between them. In an early study, Boyce and Todd (1992) reported that women having an emergency CS had more than six times the risk of developing postnatal depression 3 months postpartum in comparison to women who had vaginal deliveries [22]. Blomquist et al. (2011) found that unplanned CS was associated with dissatisfaction and distress in comparison to planned CS [14]. Rowlands and Redshaw (2012) found that unplanned CS and forcepsassisted vaginal births were associated with poorer health and wellbeing for women, with those experiencing the latter being more likely to report ongoing post-traumatic stress disorder (PTSD) type symptoms several months after the birth [23]. Women who had an instrumental birth have also reported the experience as more traumatic than SVD, with fear of childbirth being more common $[24,25]$. Large population-based studies that can identify SVD, instrumental birth and CS and discriminate between planned versus unplanned birth are needed to provide a comprehensive evaluation of what aspects of birth are most important.

Maternal postnatal adjustment, as a psychosocial outcome in these studies, has been variously defined as selfrated health [26], satisfaction [27], psychological distress $[7,11,28]$ and adjustment to parenthood [28]. These different aspects of maternal postnatal adjustment, while related, reflect different underlying concepts [29]. Studies would benefit from exploring multiple components of maternal postnatal adjustment rather than focusing on one outcome.
Finally, Carquillat, Boulvain and Guitter (2016) recommend that mode of birth not be considered in isolation when exploring its relationship with maternal postnatal adjustment [27]. A number of variables have been identified that could potentially mediate this relationship. DeLuca and Lobel (2014) reported an association between mode of birth and childbirth satisfaction that was mediated by reduced control and unmet expectations. Other studies have highlighted support and the relationship with the caregiver [30], involvement in decision-making [30], experienced control $[31,32]$ and the first moments with the newborn $[32,33]$ as important variables that are directly related to birth method and may mediate the relationship with maternal postnatal adjustment.

There is a good theoretical rationale for exploring the role of each of these factors as mediators. Perceived control is thought to influence adjustment to acute stressful events [34] and the degree to which an event is expected is considered to influence how people cope with it [35]. Both perceived control and expectations may be affected if planned mode of birth changes, resulting in poorer postnatal adjustment. Women's involvement in decision-making around the time of birth provides an important mechanism for increasing the information they receive and their sense of control over decisions that affect their wellbeing $[4,36]$. Social support is considered to be a buffer in acutely stressful events [37] and skin-to-skin contact during first moments with the baby after birth is considered to have a positive impact by elevating oxytocin, which antagonizes the flight-fight effect, decreasing maternal anxiety [38] and may also promote early parenting behaviours $[39,40]$ including breastfeeding [41].

The 2014 National Maternity Survey is a population based study conducted in England that provides detailed information on women's experience of care during pregnancy, labour and birth and after birth [33]. It has comprehensive questions on mode of birth, experience of support, involvement in decision-making, satisfaction with care, maternal wellbeing, how long until the mother held her baby, when the mother felt her baby belonged to her and infant health at 3 months. This is a unique dataset to evaluate a model that explores the direct relationship between mode of birth and postnatal maternal adjustment at 3 months and indirect relationships through psychosocial variables. We used this dataset to test the following hypotheses:

1. Mode of birth (SVD, instrumental, planned CS, unplanned CS) is associated with postnatal maternal adjustment as measured by three indicators: a composite postnatal wellbeing measure, maternal satisfaction with care during labour and birth, and maternal/infant sense of belonging.

2. Perceived control, maternal expectation, support in labour, how long until the mother held her 
baby mediate the relationship between mode of birth and the three indicators of postnatal maternal adjustment listed above.

\section{Methods}

\section{Design}

This study is a secondary analysis of a population-based survey in England, UK in 2014. Content of the questionnaire can be found in the initial survey report [33].

\section{Sample}

The survey sample was made up of a random sample of 10,000 women who had their baby in a two-week period at the beginning of January 2014 in England. Women were selected for the survey by the Office for National Statistics (ONS) from birth registrations. Women were excluded if their baby had died or they were aged less than 16 .

ONS provided information on each woman's age group, marital status, an area-based measure of deprivation (the Index of Multiple Deprivation (IMD) in quintiles), country of birth, and whether or not she had responded to the questionnaire, for this random sample of 10,000 women. This enabled responders and non-responders to be compared. This analysis included all primiparous women with singleton babies who provided information about mode of birth $(n=2139)$.

\section{Data collection}

Women in the sample received a questionnaire 3 months after birth, along with an invitation letter, an information leaflet and information sheet in 19 different languages with a Freephone contact number. Women were offered three ways to respond to the questionnaire 1) a postal questionnaire which could be completed and returned to the National Perinatal Epidemiology Unit (NPEU) in a Freepost envelope 2) to complete the questionnaire online, or 3) to complete the survey by telephone, using a Language line interpreter if needed. The questionnaires, each identifiable only by a unique reference number, were returned by post/online/phone to NPEU and logged. The initial mail out took place in April 2014. A reminder letter was sent out 2 weeks later, a further questionnaire was sent out 4 weeks after the initial mail out and again after 8 weeks, if no response had been received.

\section{Measures}

A 26 page questionnaire was completed which took women through their experience of pregnancy, labour and birth, and postnatal care and allowed them to describe the care they had received. The following items and composite variables were taken from the questionnaire.

\section{Mode of birth}

Women were asked what kind of birth they had and were given the following reply options: "Normal (vaginal) birth", "Birth using forceps", "Birth using vacuum cap on the baby's head (ventouse)" and "A caesarean (through a cut in the abdomen)". For caesarean births women were asked if the birth was "Planned and carried out before you went into labour", "Planned, but carried out after you had gone into labour", or "The result of an unforeseen problem during your labour". Due to small group size, forceps and ventouse were combined into 'Instrumental', and the two categories of planned caesarean were combined. The numbers in each group can be found in Table 1.

\section{Outcome measures}

Maternal postnatal wellbeing A composite score for postnatal wellbeing was made up of the following six health and wellbeing questions that significantly correlated with each other (Cronbach's alpha 0.66). Higher scores reflect better wellbeing and the maximum score was six.

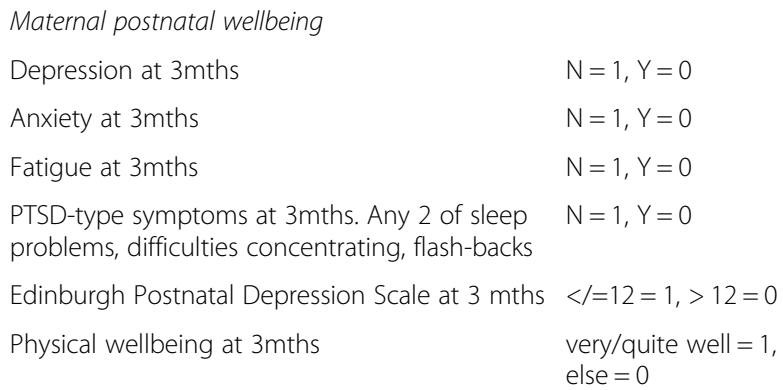

Maternal satisfaction with care during labour and birth This was a single question which asked: 'Overall, how satisfied or dissatisfied were you with the maternity care you experienced during your labour and birth' using a 5 point Likert scale with responses ranging from 'very satisfied' through to 'very dissatisfied'.

Maternal/infant sense of belonging This was one item which asked 'When did you feel your baby really belonged to you? The response levels were: 'During pregnancy', 'immediately after birth, 'in the first few days,' 'in the first few weeks,' 'only recently' and 'not quite yet.' It was scored 5 for 'During pregnancy' to 0 for 'Not quite yet'.

\section{Mediator variables}

Perceived control during labour and birth This was a composite measure of seven questions related to decision-making, receiving information, and control (Cronbach's alpha 0.81). Each item response was coded 0 or 1 and the overall score was a sum of the item 
scores, with higher scores indicating greater perceived control (maximum score $=7$ ).

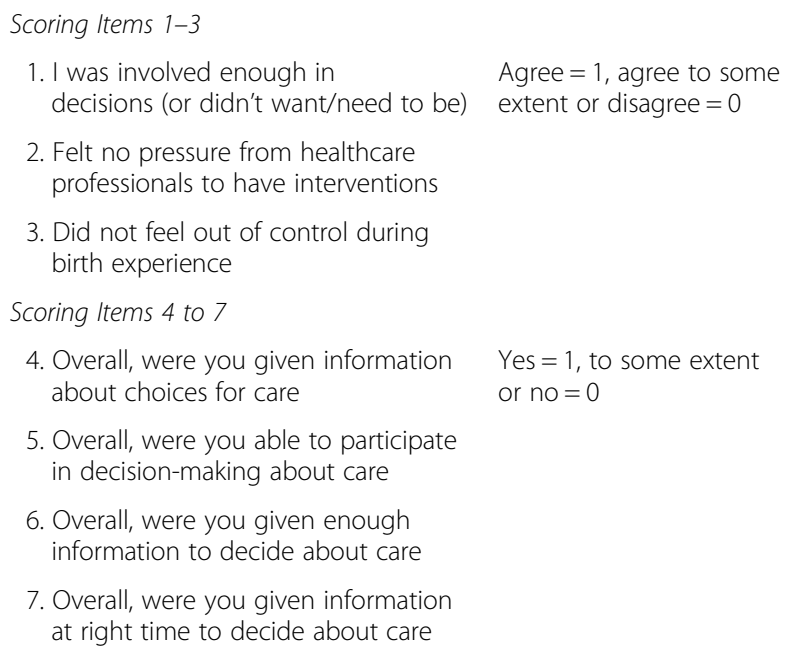

Healthcare professional (HCP) support during labour This was made up of three items scored 0 or 1 (higher scores indicated greater support, maximum score 3) and had a Cronbach's alpha of 0.82 .

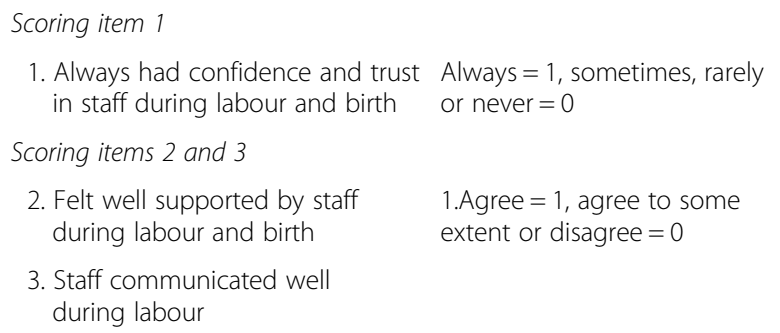

Expectations This variable was made up of one item: 'Overall how do you feel your labour and birth went?' with 'worse than you expected', 'more or less as you expected' and 'better than expected' as response options, scored from 0 to 2 .

Holding the baby This was an indicator of the time elapsed between the baby's birth and when the mother first held the baby: 'Soon after your baby was born, were you able to hold your baby?' If yes, 'How soon after birth did you hold you baby?' This was categorised into 0-2 min, 3-15 min, more than $15 \mathrm{~min}$, and women who did not hold their baby soon after birth, and was coded from 0 to 3 where $0=$ did not hold baby soon after birth, $3=$ held baby within 2 min.

Infant health at 3 months In addition to the above psychosocial mediators, a binary indicator of infant health was also included 'Does your baby have any health problems now?' (coded yes $=0$; no $=1$ ). This is in recognition that ongoing concerns about infant health after birth can impact on maternal adjustment at 3 months [42].

\section{Analysis}

Mode of birth was the categorical explanatory variable (SVD, instrumental, planned CS, unplanned CS); the mediator variables included Perceived control, Expectations, Holding the baby, Health care professional (HCP) support, and Infant health at 3 months; and Maternal adjustment was the outcome variable. Maternal adjustment was considered in three ways: Maternal postnatal wellbeing at 3 months (Model 1); Maternal satisfaction with care during labour and birth evaluated at 3 months (Model 2); and Maternal/infant sense of belonging (Model 3). Separate analyses were conducted for each measure of maternal adjustment.

The mediation analysis followed the Baron and Kenny method [43]. First, linear regression models were used to explore unadjusted univariable associations between mode of birth and each maternal adjustment outcome $(c$; not shown in Fig. 1) and between mode of birth and each potential mediator ( $a$ in Fig. 1) as an intermediate outcome. Next, regression models for the association between mode of birth and the maternal adjustment outcomes ( $c^{\prime}$ in Fig. 1) adjusting for the potential mediators ( $b$ in Fig. 1$)$ were fitted. Evidence for statistical significance in the univariable regressions was based on $\mathrm{t}$-tests for continuous variables and the ANOVA F-test for categorical variables. Where the unadjusted effects of mode of birth on potential mediators and on maternal adjustment- paths $a$ and $c$ in Baron and Kenny's mediation model - and the adjusted effect of potential mediators on maternal adjustment (path $b$ ) were statistically significant, the proportion of effect mediated was estimated as the relative change in effect between the unadjusted $(c)$ and adjusted effect of mode of birth $\left(c^{\prime}\right)$ on maternal adjustment (Fig. 1). Mode of birth was a categorical non-ordinal variable, therefore the proportion of effect mediated for each category of mode of birth was estimated relative to SVD in a series of pairwise linear regression models (Hayes \& Preacher, 2014). The path coefficients for the comparison group were set to zero. Sobel's test was used to infer whether the amount of mediation observed was statistically significant [44]. For inference, at least one significant relative mediated effect, based on Sobel's test, was interpreted as evidence of mediation of the effect of mode of birth on maternal adjustment [45]. We used a 0.05 level of significance for the regression models, but given the relatively large number of independent statistical tests conducted, we used a higher threshold of 0.001 for statistical significance in the tests for mediation [46]. All analyses were conducted using STATA 13 SE. 
Table 1 Sample characteristics (all primiparous women with singletons, with known mode of birth, $N=2139$ )

\begin{tabular}{|c|c|c|c|c|c|c|c|c|c|c|}
\hline & \multicolumn{10}{|c|}{ Mode of birth } \\
\hline & \multicolumn{2}{|l|}{ SVD } & \multicolumn{2}{|c|}{ Instrumental } & \multicolumn{2}{|c|}{ Planned CS } & \multicolumn{2}{|c|}{ Unplanned CS } & \multicolumn{2}{|l|}{ Total } \\
\hline & $\mathrm{n}$ & $\%$ & $\mathrm{~N}$ & $\%$ & $\bar{N}$ & $\%$ & $n$ & $\%$ & $n$ & $\%$ \\
\hline \multicolumn{11}{|l|}{ Maternal age $\mathrm{e}^{* * *}$} \\
\hline $16-19$ & 59 & 5.8 & 11 & 2.1 & 4 & 2.2 & 12 & 3.1 & 86 & 4.0 \\
\hline $20-24$ & 189 & 18.4 & 66 & 12.3 & 23 & 12.5 & 49 & 12.5 & 327 & 15.3 \\
\hline $25-29$ & 352 & 34.3 & 173 & 32.2 & 34 & 18.5 & 117 & 29.9 & 676 & 31.6 \\
\hline $30-34$ & 296 & 28.9 & 194 & 36.1 & 74 & 40.2 & 126 & 32.2 & 690 & 32.3 \\
\hline $35-39$ & 111 & 10.8 & 76 & 14.2 & 32 & 17.4 & 74 & 18.9 & 293 & 13.7 \\
\hline $40+$ & 19 & 1.9 & 17 & 3.2 & 17 & 9.2 & 13 & 3.3 & 66 & 3.1 \\
\hline Total (Missing $=1$ ) & 1027 & 100.0 & 537 & 100.0 & 184 & 100.0 & 391 & 100.0 & 2138 & 100.0 \\
\hline \multicolumn{11}{|c|}{ Index of Multiple Deprivation } \\
\hline 1 & 185 & 18.0 & 116 & 21.6 & 32 & 17.4 & 76 & 19.4 & 409 & 19.1 \\
\hline 2 & 212 & 20.6 & 97 & 18.1 & 32 & 17.4 & 87 & 22.3 & 428 & 20.0 \\
\hline 3 & 220 & 21.4 & 132 & 24.6 & 47 & 25.5 & 81 & 20.7 & 480 & 22.4 \\
\hline 4 & 219 & 21.3 & 122 & 22.7 & 38 & 20.7 & 73 & 18.7 & 452 & 21.1 \\
\hline 5 (most deprived) & 191 & 18.6 & 70 & 13.0 & 35 & 19.0 & 74 & 18.9 & 370 & 17.3 \\
\hline Total & 1027 & 100.0 & 537 & 100.0 & 184 & 100.0 & 391 & 100.0 & 2139 & 100.0 \\
\hline \multicolumn{11}{|l|}{ Ethnicity } \\
\hline White & 865 & 85.6 & 466 & 89.1 & 151 & 85.8 & 326 & 86.0 & 1808 & 86.5 \\
\hline Mixed & 27 & 2.7 & 8 & 1.5 & 2 & 1.1 & 7 & 1.8 & 44 & 2.1 \\
\hline Asian & 95 & 9.4 & 40 & 7.6 & 13 & 7.4 & 33 & 8.7 & 181 & 8.7 \\
\hline Black & 20 & 2.0 & 7 & 1.3 & 9 & 5.1 & 11 & 2.9 & 47 & 2.2 \\
\hline Other & 4 & 0.4 & 2 & 0.4 & 1 & 0.6 & 2 & 0.5 & 9 & 0.4 \\
\hline Total (Missing $=50$ ) & 1011 & 100.0 & 523 & 100.0 & 176 & 100.0 & 379 & 100.0 & 2089 & 100.0 \\
\hline \multicolumn{11}{|c|}{ Age left full-time education (years) } \\
\hline$<17$ & 143 & 14.1 & 72 & 13.4 & 35 & 19.6 & 54 & 13.9 & 304 & 14.3 \\
\hline $17-18$ & 268 & 26.4 & 140 & 26.1 & 47 & 26.3 & 111 & 28.5 & 566 & 26.7 \\
\hline $19+$ & 601 & 59.2 & 325 & 60.5 & 97 & 54.2 & 225 & 57.7 & 1248 & 58.8 \\
\hline Still in education & 3 & 0.3 & 0 & 0 & 0 & 0 & 0 & 0 & 3 & 0.1 \\
\hline Total (Missing = 18) & 1015 & 100.0 & 537 & 100.0 & 179 & 100.0 & 390 & 100.0 & 2121 & 100.0 \\
\hline
\end{tabular}

\section{Results}

Completed questionnaires were returned by 4571 women. Once undeliverable questionnaires were excluded from the denominator this gave a usable response rate of $47 \%$. There was significant under-representation of women who were young, living in deprived areas, and those born outside the UK [33]. However, the survey was well-completed with missing data for individual items ranging from 1.0 to $5 \%$.

The mean age of the baby at questionnaire return was 15.4 weeks ( $\mathrm{SD}=5.0$, range $12-52$ weeks for whole sample). The characteristics of the 2139 primiparous women with singleton deliveries for whom mode of birth was reported are shown in Table 1. Overall, less than half (48\%) of these women had a SVD, a quarter had an instrumental birth with forceps or ventouse, and just over a quarter (27\%) had a CS, mostly due to unforeseen problems.

\section{Hypothesis 1: Mode of birth (SVD, instrumental, planned CS, unplanned CS) is associated with postnatal maternal adjustment as measured by three indicators: a composite postnatal wellbeing measure, maternal satisfaction with care during labour and birth, and maternal/infant sense of belonging.}

Univariable analysis of the relationship between mode of birth and mediators and mode of birth and maternal adjustment outcome variables can be found in Table 2 . 


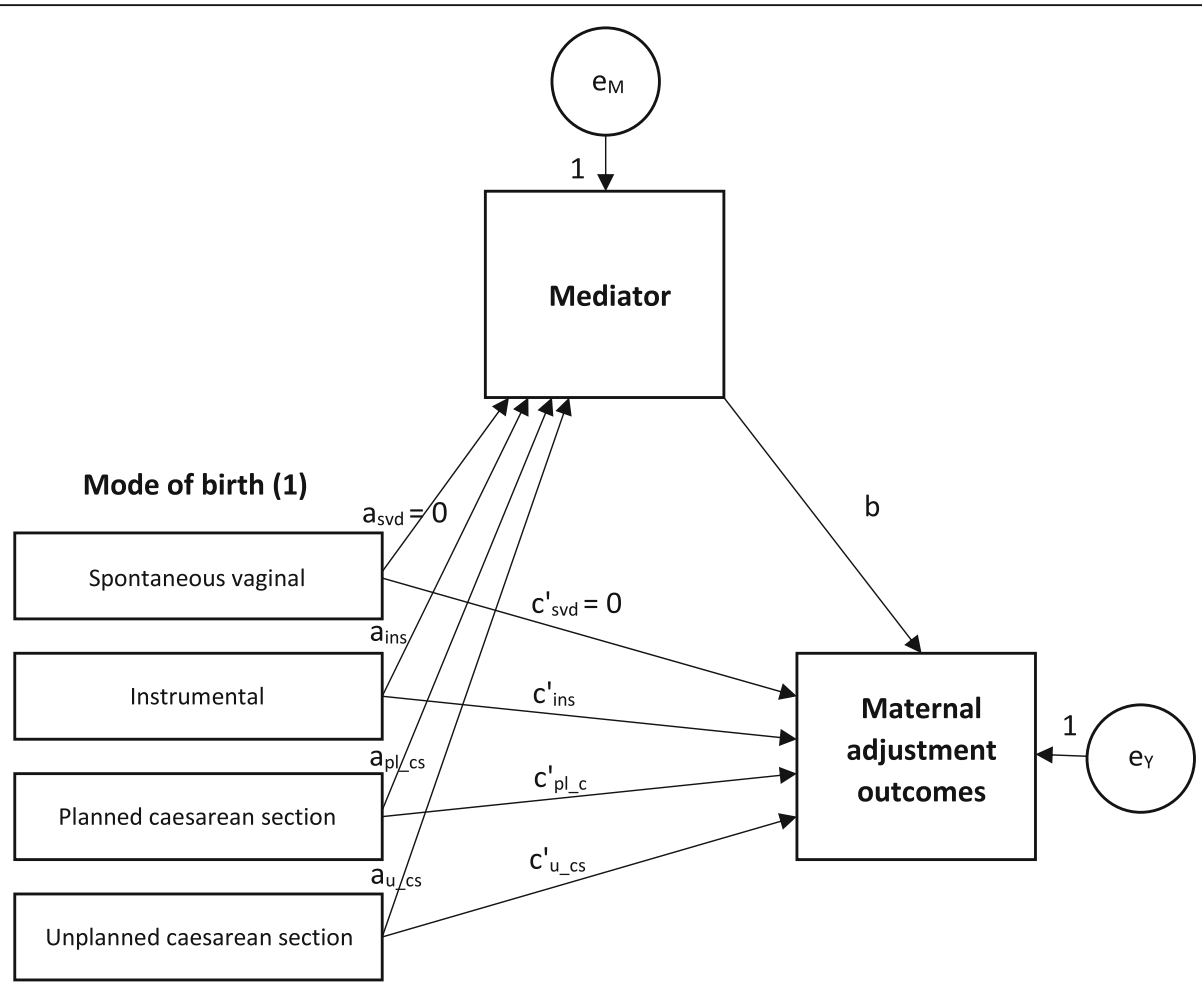

Fig. 1 Mediation model for mode of delivery and maternal adjustment outcomes

There was some evidence of an overall difference in Maternal postnatal wellbeing scores across the categories of mode of birth (F-test $p$-value $=0.0481$ ). Instrumental, planned CS and unplanned CS were associated with lower Maternal postnatal wellbeing scores compared to SVD (Table 2). Maternal satisfaction with care during labour and birth scores also differed across the categories of mode of birth (F-test p-value < 0.001): women who delivered through instrumental, planned CS and unplanned CS reported lower
Satisfaction with care during labour and birth scores than those delivering by SVD. However, there was no evidence of association between mode of birth and Maternal/infant sense of belonging $(\mathrm{F}$-test $\mathrm{p}$-value $=0.1667)$. Thus, further analyses are focussed on Maternal postnatal wellbeing and maternal satisfaction with care during labour and birth (models 1 and 2).

The association between sociodemographic variables and mode of birth or outcomes was explored. There was strong evidence of association between maternal age and

Table 2 The association of mediator variables and maternal adjustment outcomes with mode of birth

\begin{tabular}{|c|c|c|c|c|c|c|c|c|c|c|}
\hline & \multicolumn{10}{|c|}{ Mode of birth } \\
\hline & \multicolumn{2}{|l|}{ SVD } & \multicolumn{2}{|c|}{ Instrumental } & \multicolumn{2}{|c|}{ Planned CS } & \multicolumn{2}{|c|}{ Unplanned CS } & \multicolumn{2}{|c|}{ Total } \\
\hline & $\bar{N}$ & $\%$ & $\mathrm{n}$ & $\%$ & $\mathrm{n}$ & $\%$ & $\mathrm{n}$ & $\%$ & $\bar{n}$ & $\%$ \\
\hline \multicolumn{11}{|l|}{ Mediators } \\
\hline Perceived control - mean $(95 \% \mathrm{Cl})^{* * *}$ & \multicolumn{2}{|c|}{$5.00(4.87,5.12)$} & \multicolumn{2}{|c|}{$4.38(4.19,4.57)$} & \multicolumn{2}{|c|}{$4.58(4.24,4.92)$} & \multicolumn{2}{|c|}{$3.86(3.63,4.09)$} & \multicolumn{2}{|c|}{$4.60(4.51,4.70)$} \\
\hline Expectations ( $n, \%$ worse than expected) ${ }^{* * *}$ & 156 & 15.6 & 273 & 52.0 & 37 & 21.1 & 247 & 65.5 & 713 & 34.3 \\
\hline Holding baby ( $n, \%$ within 2 mins of birth) ${ }^{* * *}$ & 658 & 71.1 & 247 & 49.1 & 16 & 9.3 & 39 & 10.6 & 960 & 48.8 \\
\hline HCP support- mean $(95 \% \mathrm{Cl})^{* * *}$ & \multicolumn{2}{|c|}{$2.49(2.43,2.55)$} & \multicolumn{2}{|c|}{$2.26(2.16,2.36)$} & \multicolumn{2}{|c|}{$2.52(2.37,2.66)$} & \multicolumn{2}{|c|}{$2.09(1.96,2.21)$} & \multicolumn{2}{|c|}{$2.36(2.31,2.41)$} \\
\hline Infant health at 3 mths (n,\% with problems) ${ }^{* *}$ & 124 & 12.2 & 81 & 15.3 & 38 & 21.2 & 60 & 15.7 & 303 & 14.4 \\
\hline \multicolumn{11}{|l|}{ Outcomes - mean (95\% Cl) } \\
\hline Maternal postnatal wellbeing* & \multicolumn{2}{|c|}{$5.60(5.55,5.66)$} & \multicolumn{2}{|c|}{$5.51(5.43,5.60)$} & \multicolumn{2}{|c|}{$5.52(5.35,5.68)$} & \multicolumn{2}{|c|}{$5.44(5.33,5.55)$} & \multicolumn{2}{|c|}{$5.54(5.50,5.59)$} \\
\hline Maternal satisfaction with labour and birth*** & \multicolumn{2}{|c|}{$4.54(4.49,4.59)$} & \multicolumn{2}{|c|}{$4.28(4.19 .4 .37)$} & \multicolumn{2}{|c|}{$4.60(4.48,4.72)$} & \multicolumn{2}{|c|}{$4.16(4.05,4.27)$} & \multicolumn{2}{|c|}{$4.41(4.37,4.45$} \\
\hline Mother/Infant belonging & \multicolumn{2}{|c|}{$4.84(4.76,4.92)$} & \multicolumn{2}{|c|}{$4.77(4.65,4.89)$} & \multicolumn{2}{|c|}{$4.69(4.49,4.90)$} & \multicolumn{2}{|c|}{$4.69(4.54,4.84)$} & \multicolumn{2}{|c|}{$4.78(4.72,4.84)$} \\
\hline
\end{tabular}

${ }^{*} p<0.05,{ }^{* *} p<0.01,{ }^{* * *} p<0.001$ 
mode of birth $(p<0.001)$ with older mothers more likely to deliver surgically and some evidence of association between Index of Multiple Deprivation and Satisfaction with care during labour and birth $(p=0.031)$, with more deprived women reporting lower satisfaction. Also, age of the baby at the time of questionnaire completion was correlated with greater Maternal postnatal wellbeing $(p=0.025)$. However, overall there were only weak association of the sociodemographic variables with both mode of birth and maternal adjustment outcome and they were therefore excluded from further analyses.

Hypothesis 2: Perceived control, maternal expectation, support in labour, how long until the mother held her baby, and infant health at 3 months mediate the relationship between mode of birth and postnatal maternal adjustment as measured by a composite wellbeing measure and maternal satisfaction with care during labour and birth.
The effect of each of the potential mediators on Maternal postnatal wellbeing (Table 3) and Satisfaction with labour and birth (Table 4) is shown separately. Perceived control had the highest mediation effect $(76 \%$ of total effect mediated, $p<0.001)$ and the mediation model can be found in Fig. 2 (full data for all mediation models can be found in the Additional file 1). Control also mediated between both instrumental and unplanned CS and Satisfaction with care during labour and birth (57 and $69 \%$ of total effect mediated, $p<0.001$ and $p<0.001$ respectively). There was evidence that Expectations regarding labour and birth mediated the associations between unplanned CS and Maternal postnatal wellbeing ( $12 \%$ effect mediated, $p=0.004$ ), and between both instrumental and unplanned CS and Satisfaction with care during labour and birth (50 and $46 \%$ effects mediated, $p<0.001$ and $\mathrm{p}<0.001$ respectively). Holding the baby soon after birth significantly mediated the associations between unplanned CS and Maternal postnatal wellbeing (38\% effect mediated, $p<0.001$ ), and between both

Table 3 Unadjusted and adjusted association between mode of birth and Maternal postnatal wellbeing by mediator variable

\begin{tabular}{|c|c|c|c|c|c|}
\hline & \multirow[t]{2}{*}{ Coefficients } & \multicolumn{4}{|c|}{ Mode of birth (exposure) } \\
\hline & & SVD & Instrumental & Planned CS & Unplanned CS \\
\hline \multirow[t]{2}{*}{ Maternal postnatal wellbeing } & Unadjusted $(c)^{*}$ & 0 & $-0.09(-0.19$ to 0.02$)$ & $-0.09(-0.25$ to 0.07$)$ & $-0.16(-0.27$ to -0.04$)$ \\
\hline & Standardised & 0 & $-0.04(-0.09$ to 0.01$)$ & $-0.01(-0.04$ to 0.01$)$ & $-0.08(-0.20$ to 0.05$)$ \\
\hline \multicolumn{6}{|l|}{ Mediator } \\
\hline \multirow[t]{4}{*}{ Perceived control } & Adjusted $\left(c^{\prime}\right)^{* *}$ & 0 & - & - & $-0.07(-0.19$ to 0.05$)$ \\
\hline & Standardised & 0 & & & $-0.03(-0.08$ to 0.03$)$ \\
\hline & $\%$ Effect mediated & & - & - & 76.0 \\
\hline & Sobel p-value & & - & - & $<0.001$ \\
\hline \multirow[t]{4}{*}{ Expectations } & Adjusted $\left(c^{\prime}\right)^{* *}$ & 0 & - & - & $-0.08(-0.20$ to 0.05$)$ \\
\hline & Standardised & 0 & & & $-0.02(-0.09$ to 0.02$)$ \\
\hline & $\%$ Effect mediated & & - & - & 11.6 \\
\hline & Sobel p-value & & - & - & 0.004 \\
\hline \multirow[t]{4}{*}{ Holding the baby } & Adjusted $\left(c^{\prime}\right)^{* *}$ & 0 & - & - & $-0.04(-0.18$ to 0.10$)$ \\
\hline & Standardised & 0 & & & $-0.02(-0.08$ to 0.05$)$ \\
\hline & $\%$ Effect mediated & & - & - & 38.1 \\
\hline & Sobel p-value & & - & - & $<0.001$ \\
\hline \multirow[t]{4}{*}{ HCP support } & Adjusted $\left(c^{\prime}\right)^{* *}$ & 0 & - & - & $-0.11(-0.23$ to 0.00$)$ \\
\hline & Standardised & 0 & & & $-0.05(-0.10$ to 0.00$)$ \\
\hline & $\%$ Effect mediated & & - & - & 18.7 \\
\hline & Sobel p-value & & - & - & $<0.001$ \\
\hline \multirow[t]{4}{*}{ Infant health at 3 mths } & Adjusted $\left(c^{\prime}\right)^{* *}$ & 0 & - & - & $-0.16(-0.27$ to -0.04$)$ \\
\hline & Standardised & 0 & & & $-0.07(-0.13$ to -0.02$)$ \\
\hline & $\%$ Effect mediated & & - & - & 1.8 \\
\hline & Sobel p-value & & - & - & 0.106 \\
\hline
\end{tabular}


Table 4 Unadjusted and adjusted association between mode of birth and Satisfaction with care during labour and birth by mediator variable

\begin{tabular}{|c|c|c|c|c|c|}
\hline & \multirow[t]{2}{*}{ Co-efficient } & \multicolumn{4}{|c|}{ Mode of birth (exposure) } \\
\hline & & SVD & Instrumental & Planned CS & Unplanned CS \\
\hline \multirow{2}{*}{$\begin{array}{l}\text { Satisfaction with care } \\
\text { during labour and birth }\end{array}$} & Unadjusted $(c)^{*}$ & 0 & $-0.26(-0.36$ to -0.16$)$ & $0.06(-0.09$ to 0.21$)$ & $-0.38(-0.49$ to -0.27$)$ \\
\hline & Standardised & 0 & $-0.13(-0.17$ to -0.18$)$ & 0.01 (- 0.01 to 0.03$)$ & $-0.18(-0.23$ to 0.13$)$ \\
\hline \multicolumn{6}{|l|}{ Mediator } \\
\hline \multirow[t]{4}{*}{ Perceived control } & Adjusted $\left(c^{\prime}\right)^{* *}$ & 0 & $-0.15(-0.23$ to -0.06$)$ & - & $-0.13(-0.23$ to -0.03$)$ \\
\hline & Standardised & 0 & $-0.07(-0.12$ to -0.03$)$ & & $-0.07(-0.12,-0.02)$ \\
\hline & $\%$ Effect mediated & & 56.6 & - & 69.4 \\
\hline & Sobel p-value & & $<0.001$ & - & $<0.001$ \\
\hline \multirow[t]{4}{*}{ Expectations } & Adjusted $\left(c^{\prime}\right)^{* *}$ & 0 & $0.02(-0.08$ to 0.12$)$ & - & $-0.00(-0.12$ to 0.11$)$ \\
\hline & Standardised & 0 & $0.02(-0.03$ to 0.07$)$ & & $-0.01(-0.07$ to 0.04$)$ \\
\hline & $\%$ Effect $^{\dagger}$ mediated & & 49.8 & - & 46.0 \\
\hline & Sobel p-value & & $<0.001$ & - & $<0.001$ \\
\hline \multirow[t]{4}{*}{ Holding the baby } & Adjusted $\left(c^{\prime}\right)^{* *}$ & 0 & $-0.19(-0.30$ to -0.09$)$ & - & $-0.22(-0.35$ to -0.08$)$ \\
\hline & Standardised & 0 & $-0.10(-0.15$ to -0.05$)$ & & $-0.10(-0.17$ to -0.04$)$ \\
\hline & $\%$ Effect $^{\dagger}$ mediated & & 8.4 & - & 19.4 \\
\hline & Sobel $p$-value & & $<0.001$ & - & $<0.001$ \\
\hline \multirow[t]{4}{*}{ HCP support } & Adjusted $\left(c^{\prime}\right)^{* *}$ & 0 & $-0.11(-0.18$ to -0.04$)$ & - & $-0.11(-0.19$ to -0.03$)$ \\
\hline & Standardised & 0 & -0.05 (-0.08 to 0.02$)$ & & $-0.06(-0.10$ to -0.02$)$ \\
\hline & $\%$ Effect $^{\dagger}$ mediated & & 30.7 & - & 36.0 \\
\hline & Sobel p-value & & $<0.001$ & - & $<0.001$ \\
\hline \multirow[t]{4}{*}{ Infant health at 3 mths } & Adjusted $\left(c^{\prime}\right)^{* *}$ & 0 & $-0.24(-0.34$ to -0.14$)$ & & $-0.37(-0.48$ to -0.26$)$ \\
\hline & Standardised & 0 & $-0.12(-0.17$ to -0.07$)$ & & $-0.17(-0.22$ to -0.12$)$ \\
\hline & $\%$ Effect mediated & & 0.5 & - & 0.4 \\
\hline & Sobel p-value & & 0.127 & - & 0.125 \\
\hline
\end{tabular}

$p$ values ${ }^{*}<0.05,{ }^{* *}<0.001$

instrumental and unplanned CS and Satisfaction with care during labour and birth (8 and 19\% effect mediated, $p<0.001$ and $p<0.001$ respectively). Similarly, HCP support significantly mediated the association between unplanned CS and Maternal postnatal wellbeing (19\% effect mediated, $p<0.001$ ), and between both instrumental and unplanned CS and Satisfaction with care during labour and birth (31 and 36\% effect mediated, $p<0.001$ and $p<0.001$ respectively). Infant health (ie 'Does your baby have any health problems now?' yes or no) was NOT a significant mediator of the association between method of birth and Maternal postnatal wellbeing or Satisfaction with care during labour and birth.

\section{Discussion}

Hypothesis 1 was partially supported in that there was a difference between modes of birth and maternal postnatal adjustment as measured by Maternal postnatal wellbeing and Satisfaction with care during labour and birth. Women who had an unplanned CS had the poorest postnatal adjustment. Mode of birth was not associated with Maternal/infant sense of belonging.

Hypothesis 2 was also partially supported as four out of the five proposed mediation variables showed partial mediation of the relationship between mode of birth and both Maternal postnatal wellbeing and Satisfaction with care during labour and birth. The strongest mediator was Perceived control and the only variable not to show a significant mediation effect was Health of the infant at 3 months.

These findings highlight the importance of investigating psychosocial variables and how they relate to physical birth outcomes, such as mode of birth, as well as how psychosocial variables help to explain the impact of birth experience on subsequent outcomes, especially maternal postnatal adjustment. The findings are largely in keeping with previous studies that have looked at planned versus unplanned CS birth and in particular a recent study [47] with 3006 first time mothers that found that women who had unplanned caesarean birth had the least positive feelings overall in comparison to those who delivered by 


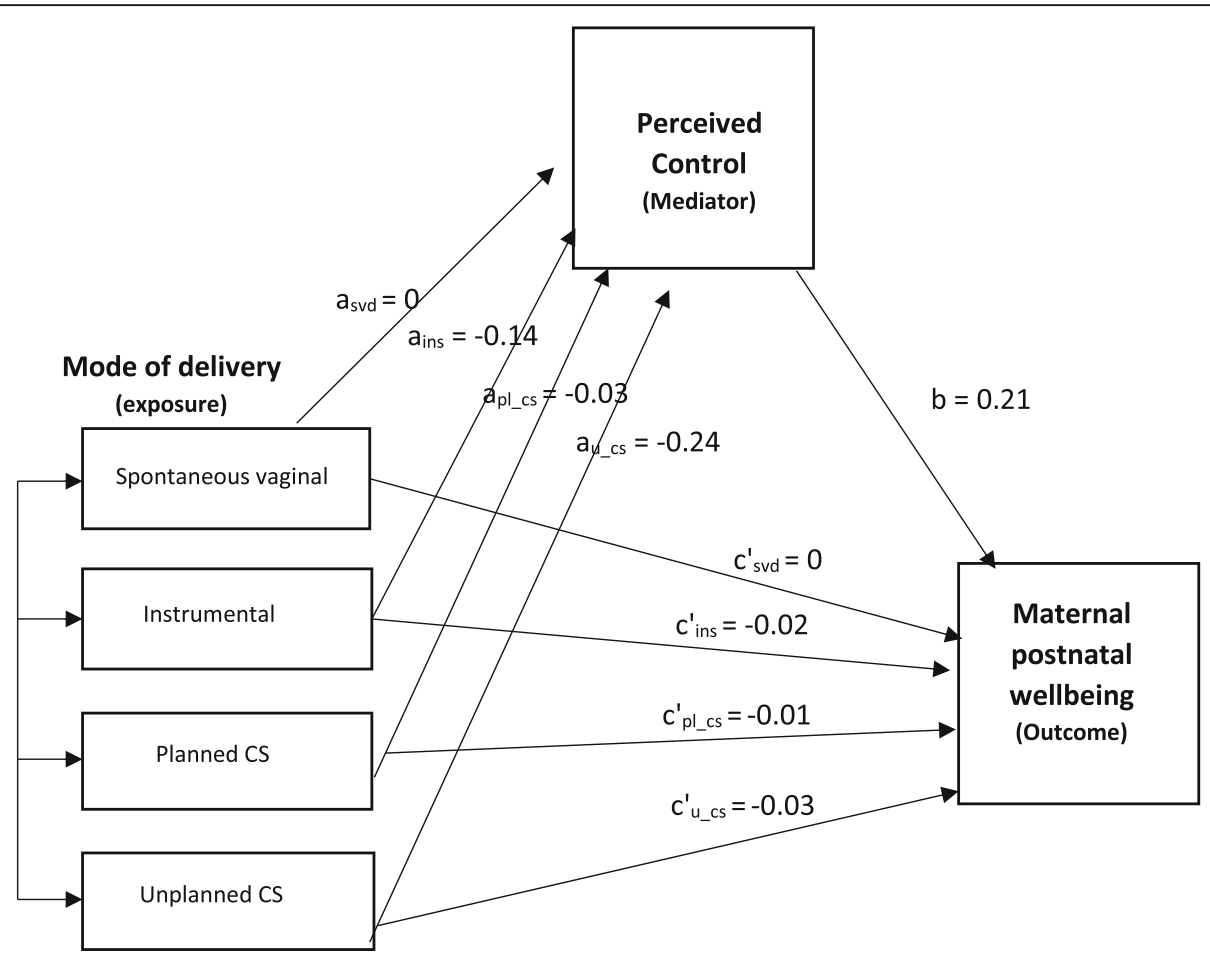

Fig. 2 The association between mode of delivery and maternal postnatal wellbeing mediated

SVD, instrumental birth or planned CS. These women were also more likely to feel disappointed and a failure.

There is a significant literature that demonstrates experienced control is highly correlated with birth experience [29, 31, 48-53]. This study goes a step further to demonstrate how mode of birth, mediated by Perceived control, is associated with Maternal postnatal wellbeing and Satisfaction with care during labour and birth. Qualitative research suggests that unplanned CS and instrumental birth have been associated with feelings of helplessness and loss of control [32] and women who have experienced instrumental birth also report feeling traumatised [25, 54]. Women who had experienced an instrumental birth have described how co-operation with hospital staff and understanding what was occurring were key factors in feeling involved and in control [54]. Our findings suggest that identifying ways to help women maintain or regain a sense of control during birth or after birth is a key component of care to support maternal postnatal adjustment.

In this study, maternal expectations were also found to mediate the relationship between mode of birth and Maternal postnatal adjustment. Some studies recommend that better preparation of women and their partners through antenatal education may be beneficial in helping women have realistic expectations about birth [32]. However maternal expectation has not always been found to predict birth experience [31, 55]. In addition, antenatal education was found to have no effect on women's experiences of birth [56] and a negative association between attending antenatal classes and birth experience has also been reported [57]. Therefore, further consideration needs to be given to the content, timing and relevance of antenatal education in regard to mode of birth.

Carquillat, Boulvain and Guittier found that women who delivered by CS experienced more negative first moments with their newborn in comparison to women who delivered vaginally [27]. Guittier et al. 2014 reported that women who had a CS felt deprived of the sensory discovery of their baby immediately after birth [32]. DeLuca and Lobel (2014) found that the most powerful predictor of satisfaction with childbirth was how soon after birth the mother held her baby [29]. Our findings confirm that holding the baby is an important and simple action that supports both satisfaction with care during labour and birth and maternal postnatal wellbeing. While it is not always possible for the woman to hold her baby straight after birth, these findings suggest women should be supported in having as much skin-to-skin contact as is feasible. It also should be noted that there is limited evidence of the impact of skin-to-skin contact at birth on the longer term maternal-child relationship [58] and preparing parents beforehand may help them think of ways of compensating for any immediate sense of loss 
of this experience [32] and promoting their relationship with their baby.

Finally, HCPs have an important role to play in the experience of women who have an unplanned birth. The very nature of unplanned birth produces a lack of continuity and challenges effective communication. Having a HCP whose primary role is to support a woman and her partner through this process may be an important mechanism for improving postnatal adjustment $[50,51,55]$.

\section{Strengths and limitations}

The main strength of the study is the use of a large and diverse population-based sample. We were able to account for CS being planned or unplanned and to look at different aspects of maternal adjustment including maternal postnatal wellbeing, satisfaction with care during labour and birth and maternal/infant sense of belonging. By conducting a mediation analysis we were able to explore the relationship between psychosocial factors, mode of birth and maternal postnatal adjustment, highlighting the complexity of these relationships and illustrating the need for providing both physical and psychological interventions at this time to optimise maternal and infant postnatal health and wellbeing.

There were a number of potential methodological limitations. The response rate was $47 \%$ and women who were younger, living in deprived areas and born outside the UK were significantly less likely to respond. We do not have psychological wellbeing data for non-responders so cannot comment if women with mental health problems were less likely to respond. The survey was conducted at 3 months postpartum with data about labour and birth being reported retrospectively. While variables such as mode of birth are likely to be accurately reported, more subjective variables such as Satisfaction with care during labour and birth may be biased by conditions at the time of reporting. However, completing the survey at 3 months postpartum avoids the initial emotions that can characterize the early postpartum period (the 'halo' effect), and minimises socially desirable responses by completing the questionnaire independently from the care provider [53, 59]. The Hayes and Preacher (2014) approach facilitated the analysis of mode of birth as a categorical non-ordinal variable but did not permit analysis of multiple mediators in the same model [45]. A further limitation is that some of the mediators and outcomes were not validated, standardised measures and some relied on single items. It is possible that the lack of association between mode of birth and maternal-infant relationship may be related to how this was measured.

\section{Implications for research and practice}

Women who have an unplanned birth, particularly unplanned CS, may need additional support to promote postnatal wellbeing and maternal satisfaction with labour and birth. There are many ways that women can be supported, for example, providing information around birth that helps parents with their expectations. Increasing support during labour and birth [60], informing and engaging with women and their partners [55] and establishing skin-to-skin contact as soon as possible after birth may all help to promote postnatal wellbeing and satisfaction [1]. It would be possible to introduce interventions at a number of different time points to optimise care for women who experience unplanned birth. However, it is currently unclear what would be most effective in improving postnatal adjustment and proposed interventions should be investigated using robust prospective methods.

\section{Conclusions}

Birth by unplanned CS is associated with poorer maternal adjustment as measured by a composite Maternal postnatal wellbeing variable. Unplanned caesarean section and instrumental birth are associated with lower maternal satisfaction with labour and birth at 3 months postpartum. The relationship was found to be partially mediated by a number of psychosocial variables. Consideration needs to be given to how to enhance support for women throughout pregnancy, labour and birth and the postpartum to promote a sense of control, a trusting relationship with their HCPs and adequately informed expectations around the time of birth. Psychosocial support interventions to promote maternal adjustment following unplanned birth need to be evaluated to identify an optimal approach to care.

\section{Additional file}

Additional file 1: Table S1. a: Mediation by Perceived control of the association between mode of delivery and maternal adjustment. b: Mediation by Expectations of the association between mode of delivery and maternal adjustment. c: Mediation by Holding baby of the association between mode of delivery and maternal adjustment. d: Mediation by HCP support of the association between mode of delivery and maternal adjustment. (DOCX $28 \mathrm{~kb}$ )

\section{Abbreviations \\ CS: Caesarean Section; HCP: Health care professional; IMD: Index of Multiple Deprivation; PTSD: Post Traumatic Stress Disorder; SVD: Spontaneous Vaginal} Delivery

\section{Acknowledgements}

We would like to thank all women who took part in the survey.

\section{Funding}

NIHR Policy Research Programme in the Department of Health \& Social Care This paper reports on an independent study which is funded by the NIHR Policy Research Programme in the Department of Health \& Social Care. The views expressed are not necessarily those of the Department. 


\section{Availability of data and materials}

The datasets generated and/or analysed during the current study are part of a larger dataset (Reference 33). The questionnaire and data set are not publicly available but are available from the corresponding author on reasonable request.

\section{Authors' contributions}

$\mathrm{FA}, \mathrm{CO}, \mathrm{JH}, \mathrm{ML}$ designed the study. $\mathrm{JH}$ and $\mathrm{CO}$ conducted the analysis and FA and ML contributed to analysis and interpretation of the findings. MQ and $\mathrm{MR}$ contributed to the interpretation of the findings. FA wrote the paper with $\mathrm{CO}, \mathrm{JH}, \mathrm{ML}, \mathrm{MQ}, \mathrm{MR}$ contributing to writing/editing of the final draft. All authors read and approved the submitted version.

\section{Ethics approval and consent to participate}

Ethical approval for the study was obtained from the NRES committee for Yorkshire and The Humber - Humber Bridge (REC reference 14/YH/0065) on 28 February 2014, with an amendment passed by the same committee on 12 May 2014. Participants consented to participate through the voluntary completion and return of their questionnaire.

\section{Consent for publication}

Not applicable.

\section{Competing interests}

The authors declare that they have no competing interests.

\section{Publisher's Note}

Springer Nature remains neutral with regard to jurisdictional claims in published maps and institutional affiliations.

\section{Author details}

${ }^{1}$ Policy Research Unit in Maternal Health and Care, National Perinatal Epidemiology Unit, Nuffield Department of Population Health, University of Oxford, Old Road Campus, Headington, Oxford OX3 7LF, UK. ${ }^{2}$ Professor of Psychology, Stony Brook University, Stony Brook, NY 11794-2500, USA.

\section{Received: 23 July 2018 Accepted: 20 February 2019}

\section{Published online: 04 March 2019}

\section{References}

1. Bigelow A, Power M, MacLellan-Peters J, Alex M, McDonald C. Effect of mother/infant skin-to-skin contact on postpartum depressive symptoms and maternal physiological stress. J Obstet Gynecol Neonatal Nurs. 2012;41(3): 369-82.

2. Betran AP, Torloni MR, Zhang JJ, Gulmezoglu AM, Section WHOWGoC. WHO statement on caesarean section rates. BJOG. 2016:123(5):667-70.

3. Niino $Y$. The increasing cesarean rate globally and what we can do about it. Biosci Trends. 2011:5(4):139-50.

4. Lobel M, DeLuca RS. Psychosocial sequelae of cesarean birth: review and analysis of their causes and implications. Soc Sci Med. 2007;64(11):2272-84.

5. Petrou S, Kim SW, McParland P, Boyle EM. Mode of birth and long-term health-related quality-of-life outcomes: a prospective population-based study. Birth. 2017:44(2):110-9.

6. Zaers $\mathrm{S}$, Waschke M, Ehlert U. Depressive symptoms and symptoms of posttraumatic stress disorder in women after childbirth. J Psychosom Obstet Gynaecol. 2008;29(1):61-71.

7. Shlomi Polachek I, Huller Harari L, Baum M, Strous RD. Postpartum anxiety in a cohort of women from the general population: risk factors and association with depression during last week of pregnancy, postpartum depression and postpartum PTSD. Isr J Psychiatry Relat Sci. 2014:51(2):128-34.

8. Gurber S, Bielinski-Blattmann D, Lemola S, Jaussi C, von Wyl A, Surbek D, et al. Maternal mental health in the first 3-week postpartum: the impact of caregiver support and the subjective experience of childbirth - a longitudinal path model. J Psychosom Obstet Gynaecol. 2012;33(4):176-84

9. De Schepper S, Vercauteren T, Tersago J, Jacquemyn Y, Raes F, Franck E. Post-traumatic stress disorder after childbirth and the influence of maternity team care during labour and birth: a cohort study. Midwifery. 2016:32:87-92.

10. Garthus-Niegel S, von Soest T, Vollrath ME, Eberhard-Gran M. The impact of subjective birth experiences on post-traumatic stress symptoms: a longitudinal study. Arch Womens Ment Health. 2013;16(1):1-10.
11. O'Donovan C, O'Donovan J. Why do women request an elective cesarean birth for non-medical reasons? A systematic review of the qualitative literature. Birth (Berkeley, Calif). 2017;45(2):109-19.

12. Cranley MS, Hedahl KJ, Pegg SH. Women's perceptions of vaginal and cesarean deliveries. Nurs Res. 1983;32(1):10-5.

13. Simons CJ, Ritchie SK, Mullett MD. Relationships between parental ratings of infant temperament, risk status, and birth method. J Pediatr Health Care. 1992;6(5 Pt 1):240-5.

14. Blomquist J, Quiroz L, MacMillan D, Mccullough A, Handa V. Mothers' satisfaction with planned vaginal and planned cesarean birth. Am J Perinatol. 2011:28(5):383-8.

15. Durik AM, Hyde JS, Clark R. Sequelae of cesarean and vaginal deliveries: psychosocial outcomes for mothers and infants. Dev Psychol. 2000;36(2):251-60.

16. Hanlon AJ, Beckmann MM. Mode of birth and early postnatal psychological morbidity. Aust N Z J Obstet Gynaecol. 2015;55(6):578-83.

17. Kochanevich-Wallace PM, McCluskey-Fawcett KA, Meck NE, Simons CJ. Method of birth and parent-newborn interaction. J Pediatr Psychol. 1988; 13(2):213-21.

18. Rijnders $\mathrm{M}$, Baston $\mathrm{H}$, Schonbeck $\mathrm{Y}$, van der Pal K, Prins M, Green J, et al. Perinatal factors related to negative or positive recall of birth experience in women 3 years postpartum in the Netherlands. Birth. 2008;35(2):107-16.

19. Spaich S, Welzel G, Berlit S, Temerinac D, Tuschy B, Sutterlin M, et al. Mode of birth and its influence on women's satisfaction with childbirth. Eur J Obstet Gynecol Reprod Biol. 2013;170(2):401-6.

20. Ulfsdottir $H$, Nissen $E$, Ryding EL, Lund-Egloff $D$, Wiberg-Itzel $E$. The association between labour variables and primiparous women's experience of childbirth; a prospective cohort study. BMC Pregnancy Childbirth. 2014:14:208

21. Sadat Z, Kafaei Atrian M, Abbaszadeh F, Karimian Z, Taherian A. Effect of mode of delivery on postpartum depression in Iranian women. J Obstet Gynaecol Res. 2014;40(1):172-7.

22. Boyce PM, Todd AL. Increased risk of postnatal depressiona after emergency caesarean section. Med J Aust. 1992;157(3):172-4.

23. Rowlands IJ, Redshaw M. Mode of birth and women's psychological and physical wellbeing in the postnatal period. BMC Pregnancy Childbirth. 2012;12:138.

24. Avasarala S, Mahendran M. A survey of women's experiences following instrumental vaginal birth. J Obstet Gynaecol. 2009;29(6):504-6.

25. Nilsson C, Bondas T, Lundgren I. Previous birth experience in women with intense fear of childbirth. J Obstet Gynecol Neonatal Nurs. 2010; 39(3):298-309.

26. Schytt $\mathrm{E}$, Waldenstrom U. Risk factors for poor self-rated health in women at 2 months and 1 year after childbirth. J Women's Health (Larchmt). 2007; 16(3):390-405.

27. Carquillat $P$, Boulvain M, Guittier MJ. How does birth method influence factors that contribute to women's childbirth experiences? Midwifery. 2016:43:21-8

28. Kingston D, Tough $\mathrm{S}$, Whitfield $\mathrm{H}$. Prenatal and postpartum maternal psychological distress and infant development: a systematic review. Child Psychiatry Hum Dev. 2012;43(5):683-714.

29. DeLuca RS, Lobel M. Diminished control and unmet expectations: testing a model of adjustment to unplanned cesarean birth. Anal Soc Issues Public Policy. 2014;14(1):183-204.

30. Hodnett ED. Caregiver support for women during childbirth. Cochrane Database Syst Rev. 2002;1:CD000199.

31. Fair CD, Morrison TE. The relationship between prenatal control, expectations, experienced control, and birth satisfaction among primiparous women. Midwifery. 2012;28(1):39-44.

32. Guittier MJ, Cedraschi C, Jamei N, Boulvain M, Guillemin F. Impact of mode of birth on the birth experience in first-time mothers: a qualitative study. BMC Pregnancy Childbirth. 2014;14:254.

33. Redshaw M, Henderson J. Safely delivered: a national survey of women's experience of maternity care 2014. Oxford: National Perinatal Epidemiology Unit; 2014.

34. Thompson SC. Will it hurt less if i can control it? A complex answer to a simple question. Psychol Bull. 1981;90(1):89-101.

35. Folkman S. Personal control and stress and coping processes: a theoretical analysis. J Pers Soc Psychol. 1984:46(4):839-52.

36. Charles C, Gafni A, Whelan T. Shared decision-making in the medical encounter: what does it mean? (or it takes at least two to tango). Soc Sci Med. 1997:44(5):681-92. 
37. Thoits PA. Social support as coping assistance. J Consult Clin Psychol. 1986; 54(4):416-23.

38. Uvnas-Moberg K, Petersson M. Oxytocin, a mediator of anti-stress, wellbeing, social interaction, growth and healing. Z Psychosom Med Psychother. 2005;51(1):57-80.

39. Uvnas-Moberg K. Oxytocin may mediate the benefits of positive social interaction and emotions. Psychoneuroendocrinology. 1998; 23(8):819-35.

40. Biro MA, Yelland JS, Brown SJ. Who is holding the baby? Women's experiences of contact with their baby immediately after birth: an Australian population-based survey. Women Birth. 2015;28(4):317-22.

41. Redshaw M, Hennegan J, Kruske S. Holding the baby: early mother-infant contact after childbirth and outcomes. Midwifery. 2014;30(5):e177-87.

42. Henderson J, Carson C, Redshaw M. Impact of preterm birth on maternal well-being and women's perceptions of their baby: a population-based survey. BMJ Open. 2016;6(10):e012676.

43. Baron RM, Kenny D. The moderator-mediator variable distinction in social psychological research: conceptural, strategic, and statistical considerations. J Pers Soc Psychol. 1986;51(6):1173-82.

44. Sobel M. Asymptotic confidence intervals for indirect effects in structural equation models. Sociol Methodol. 1982;13:290.

45. Hayes A, Preacher K. Statistical mediation analysis with a multicategorical independent variable. Br J Math Stat Psychol. 2014;67:451-70.

46. Bender R, Lange S. Adjusting for multiple testing--when and how? J Clin Epidemiol. 2001;54(4):343-9.

47. Kjerulff KH, Brubaker LH. New mothers' feelings of disappointment and failure after cesarean birth. Birth (Berkeley, Calif). 2017;45(2):109-19.

48. Bylund CL. Mothers' involvement in decision making during the birthing process: a quantitative analysis of women's online birth stories. Health Commun. 2005;18(1):23-39.

49. Hauck Y, Fenwick J, Downie J, Butt J. The influence of childbirth expectations on Western Australian women's perceptions of their birth experience. Midwifery. 2007;23(3):235-47.

50. Lavender T, Walkinshaw SA, Walton I. A prospective study of women's views of factors contributing to a positive birth experience. Midwifery. 1999;15(1):40-6.

51. Rudman A, El-Khouri B, Waldenstrom U. Women's satisfaction with intrapartum care - a pattern approach. J Adv Nurs. 2007;59(5):474-87.

52. Shorten A, Shorten B, Keogh J, West S, Morris J. Making choices for childbirth: a randomized controlled trial of a decision-aid for informed birth after cesarean. Birth. 2005;32(4):252-61.

53. Waldenstrom U, Hildingsson I, Rubertsson C, Radestad I. A negative birth experience: prevalence and risk factors in a national sample. Birth. 2004; 31(1):17-27.

54. Sjodin M, Radestad I, Zwedberg S. A qualitative study showing women's participation and empowerment in instrumental vaginal births. Women Birth. 2017:45(2):109-19.

55. Goodman P, Mackey MC, Tavakoli AS. Factors related to childbirth satisfaction. J Adv Nurs. 2004;46(2):212-9.

56. Gagnon AJ, Sandall J. Individual or group antenatal education for childbirth or parenthood, or both. Cochrane Database Syst Rev. 2007;3:CD002869.

57. Smarandache A, Kim TH, Bohr Y, Tamim H. Predictors of a negative labour and birth experience based on a national survey of Canadian women. BMC Pregnancy Childbirth. 2016;16(1):114.

58. Redshaw M, Martin C. Babies, 'bonding' and ideas about parental 'attachment'. J Reprod Infant Psychol. 2013;31(3):219-21.

59. Green JM, Coupland VA, Kitzinger JV. Expectations, experiences, and psychological outcomes of childbirth: a prospective study of 825 women. Birth. 1990;17(1):15-24

60. Ford E, Ayers $\mathrm{S}$, Wright DB. Measurement of maternal perceptions of support and control in birth (SCIB). J Women's Health (Larchmt). 2009;18(2):245-52.

Ready to submit your research? Choose BMC and benefit from:

- fast, convenient online submission

- thorough peer review by experienced researchers in your field

- rapid publication on acceptance

- support for research data, including large and complex data types

- gold Open Access which fosters wider collaboration and increased citations

- maximum visibility for your research: over $100 \mathrm{M}$ website views per year

At BMC, research is always in progress.

Learn more biomedcentral.com/submissions 